\title{
Efficacy and safety of an intravenous monoclonal anti-HBs in chronic hepatitis B patients
}

van Nunen AB, Baumann M, Manns MP, Reichen J, Spengler U, Marschner J-P, de Man RA on behalf of an International Study Group. Efficacy and safety of an intravenous monoclonal anti-HBs in chronic hepatitis B patients.

Liver 2001: 21: 207-212. (C) Munksgaard, 2001

Abstract: Background/Aims: In this study the safety and efficacy of a monoclonal anti-HBs, Tuvirumab (Mab), were investigated. Tuvirumab is a human monoclonal antibody recognizing the stable ' $a$ '-determinant of the HBsAg. Methods: We included ten chronic hepatitis B patients: four received monotherapy, and six combination therapy with interferon alpha 2b. Results: Because the development of insoluble [HBsAg-HBsAb] complexes led to adverse events, the Mab dose had to be reduced in seven patients. In nine patients treatment was stopped prematurely because of lack of efficacy, i.e. neutralization of HBsAg in serum. However, temporary $\mathrm{HBsAg}$ levels were reduced by at least $50 \%$ in all patients; in three patients receiving combination therapy, background levels of $\mathrm{HBsAg}$ in serum were reached. A loss of serum HBV-DNA was seen in three patients in the combination group, followed by $\mathrm{HBeAg}$ seroconversion in two patients. Conclusions: We conclude that Mab was not effective in achieving primary efficacy as assessed by neutralization of circulating HBsAg. Whether a combination of Mab with an antiviral agent that reduces the HBsAg load - and therefore minimizes the risk of adverse events - may result in clinical efficacy should be investigated.

\author{
Andeltje B. van Nunen', \\ Matthias Baumann', \\ Michael P. Manns ${ }^{3}$, J. Reichen ${ }^{4}$, \\ U. Spengler ${ }^{5}$, \\ Jens-Peter Marschner'2, \\ Robert A. de Man $^{1}$ on behalf of an \\ International Study Group
}

${ }^{1}$ Department of Hepatology \& Gastroenterology, University Hospital Rotterdam, The Netherlands; 2Department of Clinical Development, Boehringer Mannheim GmbH, Mannheim, Germany; ${ }^{3}$ Department of Hepatogastroenterology, Medizinische Hochschule Hannover, Germany; ${ }^{4}$ Department of Internal Medicine, Inselspital Berne, Switzerland; and ${ }^{5}$ Department of Internal Medicine, University of Bonn, Germany

Key words: hepatitis B - monoclonal antibody treatment

Robert A. de Man, Room Ca 326, Dept. of Hepatology \& Gastroenterology, University Hospital Rotterdam, P.0. Box 2040, 3000 CA Rotterdam, The Netherlands.

Tel. 3110463 3793. Fax: 31104365916. e-mail: devlaming@mdl.azr.nl

Received 5 October 2000, accepted 20 February 2001
Only a minority of hepatitis B patients benefit from current treatment strategies. Standard alpha interferon (IFN) therapy is effective in about one third of patients; prolongation increases the response rate to a maximum of $40 \%$ of patients $(1$, 2 ). The response rate depends mainly on baseline characteristics (3). Although lamivudine results in serological, biochemical and histological improvement in $60-70 \%$ of patients, viral clearance is achieved in only $16 \%$ of patients at 1 year of therapy $(4,5)$. Prolongation of lamivudine therapy beyond 1 year is hampered by the increasing occurrence of lamivudine-resistant mutants, reaching $50 \%$ after 2 years $(4,6)$. Although lamivudine and interferon monotherapy clearly has a role in anti- viral therapy for chronic hepatitis B (CHB), their present therapeutic achievements leave sufficient room for the development of new therapeutic strategies.

The efficacy of hepatitis B immunoglobulin (HBIG) in passive immune prophylaxis of orthotopic liver transplant (OLT) patients has been reported $(7,8)$. In a vaccination trial it has been shown that [HBsAb-HBsAg] complexes enhance the proliferative response of human $\mathrm{HBsAg}$-specific T-cell clones, resulting in a therapeutic effect on chronic hepatitis B infection (9). Since immunotherapy in $\mathrm{CHB}$ with passive immunization with anti-HBs was attempted by Reed et al. using polyclonal HBIG in 1973 and with mono- 
clonal antibodies by Lever et al. in 1987, no trials of anti-HBs have been performed for the treatment of $\mathrm{CHB}(10,11)$. We therefore attempted immunotherapy with Mab in the ten patients reported here.

Tuvirumab (Mab) is a human monoclonal antibody of the $\mathrm{IgG}_{1}$ subclass. It is produced by a transfectoma cell line, a recombinant mouse cell line (SP2/0), which is transfected with the genetic material of a human B lymphocyte of an HBVvaccinated patient. Regarding binding site and binding affinity with $\mathrm{HBsAg}$, Tuvirumab is identical to OST 577, produced by a 'trioma' cell line, for which clinical pilot studies were performed in OLT patients, $(12,13)$. Both antibodies have the same genetic code from the same peripheral blood lymphocyte. Mab recognizes the 'a'-determinant of the hepatitis B surface antigen. The ' $a$ '-determinant is the most stable part of the hepatitis $B$ virus and one of the major neutralizing epitopes. Anti' $\mathrm{a}$ ' antibodies are protective against almost all known subtypes of the hepatitis B virus $(14,15)$. The binding activity of Mab is 200-fold higher compared with serum-derived polyclonal antibodies (HBIG) (16).

In a phase II trial, the safety and efficacy of Mab were investigated. The trial was stopped prematurely after 10 patients had been treated with the monoclonal antibody for at least 4 weeks. The results are presented here.

\section{Patients and methods}

Patients

Fifteen patients, eight IFN nonresponders and seven IFN naive, were included in this trial after giving their informed consent. All patients were over 18 years of age and suffered from chronic hepatitis B, defined as HBsAg and HBeAg positivity in serum lasting for at least 6 months, increased alanine aminotransferase (ALT) $(50-400$ $\mathrm{U} / \mathrm{l}$ ) for the last 6 months before study entry, detectable serum HBV-DNA (liquid hybridization test), and a histological diagnosis of chronic hepatitis (portal inflammation, hepatocyte necrosis).

Exclusion criteria were: Asian origin, pregnant or lactating women, detectable serum $\mathrm{HBeAb}$, coinfection with HAV, HCV, HDV, HIV, fulminant, alcoholic or drug-induced hepatitis or decompensated liver disease. For safety reasons, patients were not included if there was a history of periarteriitis nodosa, serum sickness, psoriasis, creatinine $>1.5$ times upper limit of normal, proteinuria, micro-hematuria, major organic dysfunction or contraindication to interferon.
Medication

Patients were stratified for previous IFN therapy and randomly assigned to one of the following groups:

- Mab treatment group $(n=4)$;

- Mab+IFN treatment group (combination group) $(n=6)$;

- IFN treatment group (only IFN naive) $(n=3)$ :

- Untreated control group (only IFN nonresponders) $(n=2)$.

Interferon $\alpha-2 b$ (Intron ${ }^{\mathrm{TM}} \mathrm{A}$, Schering-Plough) was given according to the standard regimen, i.e. 5-10 MU tiw intracutaneously for 16 weeks, and was not administered on the same day as Mab in the combination group.

Mab is a lyophilisate, which has to be reconstituted with $10 \mathrm{ml}$ sterile water before administration. After reconstitution, the drug was given intravenously in $250 \mathrm{ml} 0.9 \% \mathrm{NaCl}$ over a 30 -min period.

During the first 2 weeks (escalation phase) Mab was given every 2-3 days according to a fixed dosing schedule: $20 \mathrm{mg}-20 \mathrm{mg}-40 \mathrm{mg}-40 \mathrm{mg}-80 \mathrm{mg}-80 \mathrm{mg}$ (20 mg Mab corresponds to about 360000 IU antiHBs HBIG). The dosing schedule was based on safety and efficacy data collected in a pilot study with OST-577 (14). The dose escalation should result in a step-wise reduction of the HBsAg serum level and should therefore minimize potential adverse events caused by the formation of insoluble [HBsAg-HBsAb] complexes. The aim of this escalation phase was to neutralize circulating $\mathrm{HBsAg}$, resulting in free circulating anti-HBs.

In week 3, the maintenance phase, dosing was individualized in order to maintain free anti-HBs levels in the blood. In this phase anti-HBs serum levels were measured every 2 weeks. Further Mab doses were administered depending on the antiHBs levels, according to the following schedule:

- serum anti-HBs level $>5 \mu \mathrm{g} / \mathrm{ml}$ (corresponds to about 90000 IU/l HBIG): no further Mab administration for the next 2 weeks;

- serum anti-HBs level $>1 \mu \mathrm{g} / \mathrm{ml}$ (corresponds to about $18000 \mathrm{IU} / \mathrm{l} \mathrm{HBIG)}$ but $<5 \mu \mathrm{g} / \mathrm{ml}$ : 1 single dose of $80 \mathrm{mg}$ Mab or of the individual maximum tolerated dose (MTD, see critical events) for the next 2 weeks;

- serum anti-HBs level $<1 \mu \mathrm{g} / \mathrm{ml}: 5$ doses (every 2 days) of $80 \mathrm{mg} \mathrm{Mab}$ or of the MTD for the next 2 weeks. If free serum anti-HBs levels were not reached after this frequent dosing, treatment was stopped for reasons of feasibility.

\section{Critical events}

From the results of the above-mentioned pilot study with OST-577, it was anticipated that the de- 
velopment of adverse events in patients receiving Mab would be mainly related to the formation of insoluble [HBsAg-HBsAb] complexes. For safety reasons critical events were defined: anaphylactic reactions type I, cardiovascular reaction during or within $3 \mathrm{~h}$ after infusion (shock index $>1.2$, hypertension), generalized dermatological reactions, severe arthralgia, shaking chills/rigors, increase in body temperature $>1.5^{\circ} \mathrm{C}\left(2.5^{\circ} \mathrm{F}\right)$. The following laboratory parameters were considered critical adverse events: micro-hematuria, proteinuria, serum creatinine and urea $>150 \%$ of initial value, a relevant decrease in serum albumin or an increase of serum ALT $5 \times$ higher initial value or $>800$ IU/l.

If critical events occurred during the therapy, Mab dosing was stopped until the event resolved, and afterwards therapy was continued with a $50 \%$ reduced dose, which was considered the individual maximum tolerated dose (MTD). Frequency of dosing of MTD was as described above.

\section{Laboratory methods}

The primary endpoint of the study was the development and maintenance of free anti-HBs levels. Secondary reduction of $\mathrm{HBsAg}$ and changes in HBV DNA and ALT were measured. All serum samples were stored at $-20^{\circ} \mathrm{C}$, and $\mathrm{HBV}$ markers were assessed centrally. HBV-DNA was quantified by liquid hybridization (Digene-Murex, UK). $\mathrm{HBeAg}$ and anti-HBe (qualitatively) were measured using ENZYMUN ${ }^{\mathrm{TM}}$ tests (Boehringer Mannheim, Germany). Anti-HBs ( $\mu \mathrm{g} / \mathrm{ml})$ was detected with a specific double-antigen ELISA (enzyme-linked immunosorbent assay) using biotinylated wild-type HBsAg, which was immobilized on a streptavidin-coated tube, as the solid phase. The bound antibodies were detected by binding to a horseradish peroxidase conjugated wild-type HBsAg catalyzing the formation of a colored product (ENZYMUN ${ }^{\mathrm{TM}}$ tests, Boehringer Mannheim, Germany). HBsAg (U/ml) was measured by a standard MEIA (microparticle enzyme immuno- assay) (Abbott Imx System). A monoclonal HBsAg-antibody that specially binds HBsAg from serum is immobilized to microparticles. The bound $\mathrm{HBsAg}$ is detected with biotinylated polyclonal goat anti-HBs and a polyclonal rabbit anti-biotin antibody conjugated with alkaline phosphatase catalyzes the formation of a fluorescent product.

The study was performed according to good clinical practice guidelines and the Declaration of Helsinki. All local Medical Ethics Committees approved the protocol.

\section{Results}

Fifteen patients were included in the trial: ten received Mab (four monotherapy and six combination therapy with interferon). Baseline characteristics are listed in Table 1.

\section{Safety}

No drug-related serious adverse event was observed. A summary of all adverse events probably or possibly related to Mab is demonstrated in Table 2. Eight out of ten patients experienced adverse events probably related to the administration of Mab. In seven patients, four patients in the Mab group and three patients in the combination group, critical adverse events occurred. Shaking chills/rigors partially combined with fever were reported 5 times for three patients, one in the combination group and two in the Mab group. Proteinuria and micro-hematuria were reported for three patients, two in the combination group and one in the Mab group. Flu-like syndrome was reported twice in one patient of the combination group.

Shaking chills/rigors, fever and flu-like syndrome resolved within hours after infusion, one patient received an $\mathrm{H}_{2}$-antagonist and in some cases paracetamol was used. Proteinuria and micro-hematuria resolved within a few days after withdrawal of therapy. According to the study pro-

Table 1. Baseline characteristics of patients. Data are expressed as median (min-max)

\begin{tabular}{lcccc}
\hline & $\begin{array}{c}\text { Mab } \\
\text { treatment group }\end{array}$ & $\begin{array}{c}\text { Mab+IFN } \\
\text { treatment group }\end{array}$ & $\begin{array}{c}\text { IFN } \\
\text { treatment group }\end{array}$ & $\begin{array}{c}\text { Untreated } \\
\text { control group }\end{array}$ \\
\hline Patients & 1 IFN naive & 3 IFN naive & 3 IFN naive & 2 IFN nonresponders \\
& 3 IFN nonresponders & 3 IFN nonresponders & & $29(28-30)$ \\
Age (years) & $55(39-63)$ & $39(19-46)$ & $37(24-48)$ & $1 / 1$ \\
Gender (male/female) & $4 / 0$ & $4 / 2$ & $2 / 1$ & $3550(900-6200)$ \\
HBsAg (U/ml) & $36750(1740-72000)$ & $2835(2200-22200)$ & $43200(6200-73000)$ & $556(67-1045)$ \\
HBV DNA (pg/ml) & $2149(467-6130)$ & $152(8-5065)$ & $3755(2641-33220)$ & $132\left(34^{*}-230\right)$ \\
ALT $(\mathrm{U} / \mathrm{l})$ & $90(65-116)$ & $100\left(27^{*}-199\right)$ & $166(144-199)$ & \\
\hline
\end{tabular}

* Protocol violator.

IFN, interferon. ALT, alanine aminotransferase. 
Table 2. Summary of adverse events (AE) probably or possibly related to Mab

\begin{tabular}{|c|c|c|c|c|}
\hline & $\begin{array}{c}\mathrm{AE} \\
\text { (no measures) }\end{array}$ & $\begin{array}{c}\text { Critical AE } \\
\text { (dose reduction) }\end{array}$ & $\begin{array}{c}\text { Critical } A E \\
\text { (temp. stop of treatment }+ \\
\text { dose reduction) }\end{array}$ & Total AE \\
\hline Chills & 1 & 3 & 0 & 4 \\
\hline Fever & 0 & 2 & 0 & 2 \\
\hline Abdominal pain & 1 & 0 & 0 & 1 \\
\hline Tinnitus & 1 & 0 & 0 & 1 \\
\hline Syncope & 1 & 0 & 0 & 1 \\
\hline Dyspnea & 2 & 0 & 0 & 2 \\
\hline Flu-like syndrome & 0 & 2 & 0 & 2 \\
\hline Lower back pain & 1 & 0 & 0 & 1 \\
\hline Leukopenia & 1 & 0 & 0 & 1 \\
\hline Proteinuria & 1 & 0 & 3 & 4 \\
\hline Micro-hematuria & 0 & 0 & 1 & 1 \\
\hline
\end{tabular}

tocol, all seven patients were rechallenged with a $50 \%$ reduced Mab dose (MTD) after the events resolved. No further critical event was observed.

\section{Efficacy}

Mab was administered over a period of 27-59 days. In eight out of ten cases Mab was discontinued prematurely according to the study protocol, because a frequent treatment of 5 infusions in 2 weeks during one cycle in the maintenance phase did not result in free anti-HBs serum levels. One patient was withdrawn from further treatment as scheduled prematurely; no free anti-HBs was detectable. Seven of these eight patients received a reduced Mab dose (MTD) because of critical events: $40 \mathrm{mg}(n=3)$ and $20 \mathrm{mg}(n=4)$. In two patients the administration of Mab was withdrawn prematurely because the study was stopped; in one patient anti-HBs was detectable.

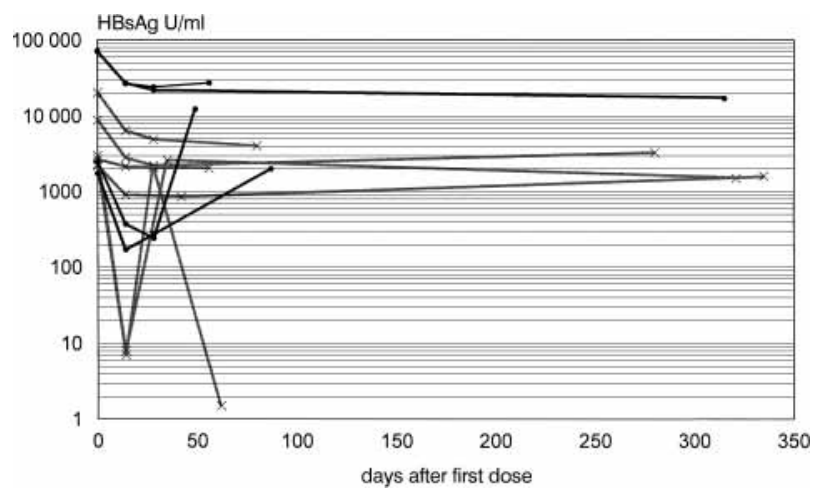

Fig. 1. HBsAg levels (U/ml) measured before start of therapy, on day 14,27 , at the end of treatment and end of follow up after administration of Mab in the monotherapy $(\bullet)$ or combination therapy $(\times)$ group.
Thus, none of the patients had a sustained clearance of serum HBsAg with the described dose regimen. In nine out of ten patients treated with Mab the treatment was stopped prematurely because free anti-HBs levels could not be achieved.

HBsAg levels were reduced by at least $50 \%$ in all ten patients during Mab treatment in both groups (monotherapy and combination). Fig. 1 shows the individual HBsAg curves. In three out of six patients in the combination group HBsAg levels were transiently decreased to background levels on various occasions, coinciding with free anti-HBs levels in the serum. A relapse of HBsAg above pretreatment levels after stopping treatment was observed in two patients in the Mab group. The relative changes of HBsAg serum levels for these ten patients at the end of therapy and end of follow-up (EFU) are demonstrated in Fig. 2.

In the IFN and untreated control group HBsAg levels fluctuated considerably. A temporary drop

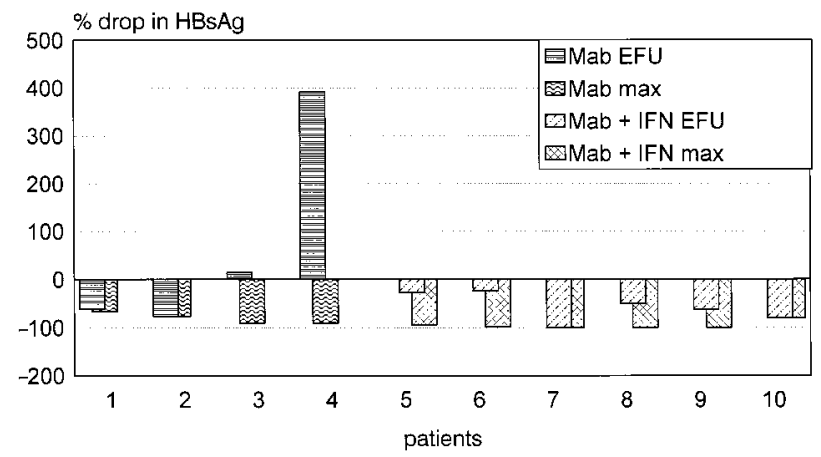

Fig. 2. The maximal (max) drop in $\mathrm{HBsAg}(\mathrm{U} / \mathrm{ml})$ and the percentage decrease in HBsAg at the end of follow-up (EFU) per patient in the monotherapy (Mab) and combination (Mab + IFN) group. In seven patients HBsAg levels increased again at the EFU, in three patients minimal HBsAg levels were reached at the EFU. 
of at least $50 \%$ was observed in two out of five patients, while in another patient HBsAg increased by $100 \%$.

With respect to the HBV-DNA levels, three patients in the combination group exhibited a loss of HBV-DNA after about 1 week, which was maintained until the end of follow-up, i.e. 8-46 weeks after start of treatment, IFN was continued in all cases during this period. $\mathrm{HBeAg}$ seroconversion was seen in two of these three patients. More than $50 \%$ reduction of HBV DNA was observed in the other three patients treated with combination therapy. In the other treatment groups no clinically relevant changes in HBV DNA levels were observed.

ALT decreased by $30 \%$ in the patients treated with Mab, which implies normalization of ALT in two out of ten patients, one patient treated with combination therapy and one with monotherapy. No clinically relevant changes in ALT were observed in the untreated and IFN-treated patients, which was expected considering the short observation period.

\section{Discussion}

The mode of action of passive immunization in hepatitis B patients is only partially known. Monoclonal or polyclonal antibodies bind $\mathrm{HBsAg}$, i.e. virions, filaments and spheres that are circulating as free particles in the blood or that are presented at the surface of cells. Consequently, the infection of noninfected cells via circulation should be inhibited. This assumption is supported by results generated during the administration of $\mathrm{HBIG}$ in OLT patients and by results of HBIG treatment for interruption of vertical transmission of the virus in neonates of HBsAg-positive mothers and after needle-stick injuries $(8,17,18)$.

Antibodies might have an indirect effect on cellular immune response via ADCC (antibody dependent cellular toxicity) by binding and activation of NK cells, or other so far only incompletely understood mechanisms. This hypothesis is supported by results from a vaccination trial, in which the administration of [HBsAg-HBsAb] complexes resulted in an enhanced proliferative response of human HBsAg-specific T-cell clones, producing a therapeutic effect in CHB patients (9). The concept of immune complexes acting as a strong immune stimulus for humoral immunity is further supported by experimental work (19). Furthermore, coating of HBV-infected hepatocytes may stimulate the leukocyte-mediated phagocytosis (opsonization) (20). In vivo and in vitro (mice model) IgGanti-HBs can stimulate T-helper cells to produce lymphokines, which promote antibody synthesis by autologous B lymphocytes (21). In chronic hepatitis B patients, excess circulating HBsAg may paralyze the immune system, enabling the virus to survive (high dose tolerance induction) (7). A reduction of serum HBsAg therefore might result in a reactivation of the endogenous immune system (15).

In this trial the most important finding as to efficacy was that sustained clearance of serum HBsAg was not achieved in any of the Mab-treated patients using the described dose regimen. In nine out of ten patients treated with Mab the treatment was stopped prematurely because the primary goal of reaching and maintaining free anti-HBs levels could not be achieved. On the other hand, it could be shown that Mab recognized and cleared HBsAg from the serum to various degrees. Only in the combination therapy group serum did HBsAg decrease transiently to background levels in three patients. Theoretically, this may also reflect a lower production of HBsAg particles because of a reduction of infected hepatocytes in these patients. However, in case of stimulation of the cellular immune system, one would expect an elevation of serum transaminases. None of the ten patients treated with Mab showed a peak in transaminase activity during the treatment or follow-up.

Only in the combination group was serum HBsAg decreased transiently to background levels in three patients. However, it has to be noted that these three patients had relatively low pretreatment HBsAg levels. In general, patients with lower baseline HBsAg levels had a better response. Therefore, an additional effect of IFN on HBsAg serum levels in the combination group, especially in the first weeks of therapy, is unlikely.

With respect to the HBV-DNA, however, it seemed that the combination of Mab with IFN is clearly superior to each compound alone. Only in the combination group did three patients show a sustained loss of HBV-DNA. In two of these, this was even combined with an $\mathrm{HBeAg}$ seroconversion when the study was stopped, about 8 to 46 weeks after the start of treatment. Since IFN treatment was continued in all cases, even if Mab treatment was stopped prematurely, it is not possible to discern the relative contribution of the two compounds to this positive development, i.e. it cannot be ruled out that this simply reflects the wellknown effect of IFN.

The critical adverse events seem to be caused by the development of insoluble [HBsAg-HBsAb] complexes after Mab infusion. This indicates again that the antibody is highly effective in binding the antigen and furthermore that the chosen dosing schedule was not sufficient in terms of a safe neutralization of $\mathrm{HBsAg}$. There was no predictor for the development of these critical events. However, 
it is likely that after reduction of $\mathrm{HBsAg}$ following Mab administration the amounts of antigen and antibody draw near an 'equivalence range', combined with an increased risk of development of insoluble antigen-antibody complexes.

With respect to the very limited sample size and treatment/observation period, it is obviously not possible to judge whether the described effects on serum markers of CHB could potentially be translated into clinically meaningful results if the treatment could be maintained by the use of an alternative regimen. The most appropriate approach appears to be a substantial reduction of $\mathrm{HBsAg}$ before initiating the Mab treatment and a maintained blocking of viral transcription, e.g. by preand concomitant treatment with nucleoside analogs. This may prevent the occurrence of insoluble [HBsAg-HBsAb] complexes and may facilitate the complete clearance of HBsAg and viral particles by the monoclonal antibody.

\section{Acknowledgements}

This study was supported by a grant from Boehringer Mannheim $\mathrm{GmbH}$, Germany.

Participants in the international study group were: Prof. Katz, Long Beach, CA, Prof. Manns, Hannover, Prof. Murphy, Savannah, GA, Prof. Pruitt, Nashville, TN, Prof. Reichen, Bern, Prof. Reindollar, Charlotte, NC, Prof. Schalm, Rotterdam, Prof. Shiffman, Richmond VA, Prof. Spengler, Bonn and Prof. Warnes, Manchester.

\section{References}

1. Wong D K, Cheung A M, O'Rourke K, Naylor C D, Detsky A S, HeAthCOTE J. Effect of alpha-interferon treatment in patients with hepatitis B e antigen-positive chronic hepatitis. Ann Intern Med 1993; 119: 312-23.

2. Janssen H L A, Gerken G, Carreno V, et al. Alpha interferon for chronic hepatitis B infection: increased efficacy of prolonged treatment. Hepatology 1999; 30: 238-43.

3. Krogsgaard K, Bindslev N, Christensen E, et al. The treatment effect of alpha interferon in chronic hepatitis $\mathrm{B}$ is independent of pre-treatment variables. Results based on individual patient data from 10 clinical controlled trials. J Hepatol 1994; 21: 646-55.

4. Lai C L, Chien R N, Leung N W, et al. A one-year trial of lamivudine for chronic hepatitis B. N Engl J Med 1998; 339: 61-8.

5. Schalm S W, Heathcote J, Cianciara J, et al. Lamivudine and alpha interferon combination treatment of patients with chronic hepatitis B infection: a randomised trial. Gut 2000; 46: 562-8.

6. Honkoop P, Niesters H G M, Man R A de, Osterhaus A D, Schalm S W. Lamivudine resistance in immunocompetent chronic hepatitis B: incidence and patterns. J Hepatol 1997; 26: 1393-5.

7. Man R A de, Metselaar H J, Heijtink R A, Schalm S W. Long-term application of human hepatitis-B immunoglobulin to prevent hepatic allograft infection. Neth J Med 1993; 43: 74-82.

8. Samuel D, Müller R, Alexander G, et al. Liver transplantation in European patients with the hepatitis B surface antigen. N Engl J Med 1993; 329: 1842-7.

9. Wen Y M, Wu X-H, Hu D-C, et al. Hepatitis B vaccine and anti-HBs complex as approach for vaccine therapy. Lancet 1995; 345: 1575-6.

10. Reed W D, Eddlestone A L W, Cullens H, et al. Infusion of hepatitis B antibody in antigen-positive active chronic hepatitis. Lancet 1973; 5: 1347-51.

11. Lever A M L, Waters J, Brook M G, et al. Monoclonal antibody to HBsAg for chronic hepatitis B virus infection with hypogammaglobulinaemia. Lancet 1990; 335: 1529.

12. Östberg L, Pursch E. Human $\times($ Mouse $\times$ Human $)$ hybridomas stable producing human antibodies. Hybridoma 1983; 4: 361-7.

13. Fung J, Östberg L, Shapiro R, Todo S, Demetrius A, STARZL T. Human monoclonal antibody against hepatitis B surface antigen in preventing recurrent hepatitis B following liver transplantation. In: Hollinger B F, Lemon S M, Margolis $\mathrm{H}$ eds. Viral hepatitis and liver disease. Baltimore: Williams \& Wilkins, 1990: 651.

14. Östberg L. Human monoclonal antibodies in transplantation. Transplant Proc 1992; 24: 26-30.

15. Gerlich W. Structure and molecular virology. In: Zuckermann A J, Thomas H C eds. Viral hepatitis. New York: Churchill Livingstone, 1993: 83-112.

16. Ehrlich P H, Moustafa Z A, Justice J C, Harfeldt K E, Kelley R L, Ostberg L. Characterisation of human monoclonal antibodies directed against hepatitis B surface antigen. Human Antibody Hybridomas 1992; 3: 2-7.

17. Ip H M, Lelie P N, Wong V C, Kuhns M C, Reesink H W. Prevention of hepatitis B virus carrier state in infants according to maternal serum levels of HBV DNA. Lancet 1989; 8635: 406-10.

18. Beasley R P, Hwang L Y, Lin C C, et al. Hepatitis B immune globulin (HBIg) efficacy in the interruption of perinatal transmission of hepatitis B virus carrier state. Lancet 1981; 8234: 3888-93.

19. McCluskie M J, Wen Y M, Di Q, Davis H L. Immunization against hepatitis $\mathrm{B}$ virus by mucosal administration of antigen-antibody complexes. Viral Immunol 1998; 11: 245-52.

20. Wawrzynczak E J. Antibody therapy. Oxford, UK: Bios Scientific Publishers, 1995.

21. Celis E, Abraham K G, Miller R W. Modulation of the immunological response to hepatitis $\mathrm{B}$ virus by antibodies. Hepatology 1987; 7: 563-8. 